\title{
Special issue on leveraging the IS organization for business value creation
}

\author{
Gwanhoo Lee ${ }^{1}$, William H DeLone ${ }^{1}$, Margaret Tan ${ }^{2}$, Martha Corrales ${ }^{3}$ \\ ${ }^{1}$ American University, Washington DC, USA; \\ ${ }^{2}$ Institute of High Performance Computing Agency for Science, Technology and Research (A*STAR), Singapore; \\ ${ }^{3}$ Tecnologico de Monterrey, Monterrey, Mexico \\ Correspondence: \\ Gwanhoo Lee, Kogod School of Business, American University, Washington DC, USA. \\ E-mail: glee@american.edu
}

Journal of Information Technology (2014) 29, 111-113. doi:10.1057/jit.2014.4; published online 8 April 2014

W e are pleased to introduce this special issue of the Journal of Information Technology on Leveraging the IS Organization for Business Value Creation. While organizations continue to seek ways to leverage information technology (IT) to create business value (Petter et al., 2012), an ever-increasing rate of IT innovation combined with new service delivery models presents unprecedented challenges (Yoo et al., 2010) and opportunities. The IS organization finds it very difficult to keep up with, let alone to lead, rapid development of mobile computing, social media, cloud computing, virtualization, business analytics, artificial intelligence, and the internet of things. The increased complexity of IT applications and infrastructure forces organizations to spend more resources in keeping the lights on and to allocate less resources in creating new business value (Xia and Lee, 2005).

Outsourcing, offshoring, and Software as a Service are changing the traditional role and expectation of the IS organization in delivering business value (Gregory et al., 2013). In-house proprietary systems have been largely replaced by standardized, off-the-shelf, open systems. With the commoditization of IT, every organization has access to the same technology. Consequently, a sustainable source of competitive advantage does not lie in technology per se but in the business-IS collaboration that facilitates the realization of the potential value of technology. An organization creates business value not only through its internal business-IS dialog, but also co-creates greater value by collaborating with other organizations, customers, and even the public through a broader business-IS dialog (Grover and Kohli, 2012).

Creating the business value through IT has been one of the major research topics in the IS field. Over the last decade, there has been an important debate on whether or not IT matters as a source of competitive advantage (Carr, 2003; DeJarnett et al., 2004). Furthermore, researchers and practitioners have been engaged in a related debate on whether the IS organization is a cost center or a value creator. While empirical evidence generally supports a positive effect of IT on organizational performance (Aral and Weill, 2007; Han et al., 2011; Kim et al., 2011), some of the fundamental questions about
IT-value creation remain unaddressed or only partially addressed. For example, the definition of business value of IT is still ambiguous $(\mathrm{Oz}, 2005)$ and we have limited understanding about the process by which IT contributes to business value and the role of the IS organization in the process (Schryen, 2013). Furthermore, despite the longstanding interest in the digital government (Lee and Kwak, 2012), little is understood about how IT creates value in the public sector and about the role the IS organization plays in the value creation process.

This special issue recognizes the continuing challenges and opportunities facing the IS organization in terms of creating the value for a variety of stakeholders. The special issue aims to identify effective strategies, governance structures, capabilities, social actions, and business and technical processes that enable IS organizations and teams to successfully deliver meaningful value to its stakeholders. It investigates the roles that IS professionals, managers, and teams play in creating and co-creating value not only for commercial organizations but also for governments. Thirty-eight submissions were reviewed and five papers were eventually selected for this special issue.

The first paper by Anne Quaadgras, Peter Weill, and Jeanne W. Ross, based on literature reviews and evidence from 20 case studies, proposes a framework of management commitments consisting of strategic choice-making, development of digital platforms, working smarter with information, and action-oriented assessment. This paper suggests that commitment is an overarching concept that brings together many of the important management practices identified in the IT-value literature. The proposed framework, tested via a survey of 210 firms, demonstrated that firms that have been more effective in making such commitments have shown a higher business impact of IT on financial performance. The framework provides a comprehensive understanding of the role of management commitment in terms of influencing the impacts of IT on organizations. Indeed, the framework would help practitioners as well as researchers gain a better understanding of the factors that influence the successful adoption and 
The fifth paper by Min-Seok Pang, Gwanhoo Lee, and deployment of strategic IT infrastructure and platforms which in turn would help management to effectively justify IT investments.

The second paper by Arne Buchwald, Nils Urbach, and Frederik Ahlemann investigates important questions on IT governance. It combines an extensive literature review and interviews with 28 IT decision makers at 19 different organizations to develop a holistic, end-to-end model for IT governance success. The model identifies IT governance success determinants and subsequent impacts on IT organization success including a new IT success construct labeled Transformational Readiness of IT, likely an important enabler to organization innovation. In addition to validating important IT governance success factors found in the prior literature, the executive interviews uncover two new factors for IT governance success: adequacy of IT governance regulations and understanding of the IT-value chain. The model will provide a comprehensive framework for future research in IT governance and its impacts. It also provides practitioners with a better understanding of the factors that influence the success of their governance program as well as the potential outcomes of their efforts. Knowledge of the potential outcomes of IT governance obtained from this study can help justify IT governance investments and guide IT governance decision making.

The third paper by Katja Walentowitz, Daniel Beimborn, and Tim Weitzel uses social network analysis methods to investigate how the social network structure of business and IS actors influence the effectiveness of modifying IT applications in production mode. The authors argue that, compared with value creation through new systems development, value creation through maintenance of existing systems has been understudied. To fill this gap, this study focuses on identifying and explaining effective social structures for the business/IT interaction at the operational level. A social network analysis of the data obtained from 7 case studies including 88 interviews and surveys reveals that application system changes are likely to be more successful when there exist dedicated interface actors between business and IT, when interface actors are strongly connected to many interface actors of the other unit, and when interface actors are strongly connected to many actors within their own unit. In addition to quantitative social network analysis, this study triangulates the findings with qualitative analysis of interview data.

The fourth paper by Heikki Lempinen and Risto Rajala focuses on social actions and interplays among different stakeholders involved in IT service realization. Given that IT needs are served through increasingly complex configurations of multiple actors, organizations, and technologies, it is important to understand how multiple actors interplay to create business value. Drawing upon the social process model and the social action perspective, this paper enriches the current understanding of business value creation in IT service delivery by infusing the service logic with conventional IT management perspectives. From qualitative analysis of two cases including interviews with users, process owners, project managers, and decision makers, this study finds that the IS organization contributes to increasing stakeholder-perceived value in IT service realization by enabling direct social action within an IT service system (i.e., a constellation of actors), by coordinating decisions and fostering emancipative activities, and by integrating knowledge resources.
William DeLone is an invited (though still peer-reviewed) contribution to this special issue. This paper complements the other four papers by introducing the notion of public value of IT in government organizations. While business value of IT has been extensively studied in the IS field, this has not been the case for public value of IT in part because of a lack of theoretical bases for investigating IT value in the public sector setting. This paper addresses this shortcoming. This study first identifies key public sector IT resources including digitized administrative processes, online public interactive interfaces and so on, as well as key public sector organizational capabilities including public service delivery capability, public engagement capability, resource acquisition capability and so on. Drawing upon the public value management theory that emphasizes the proactive role of public managers in creating pubic value, this paper presents a theoretical model that delineates the paths from IT resources to organizational performance via organizational capabilities. Furthermore, this paper posits several propositions on the mechanisms by which IT resources advance public value frontiers by resolving conflicts of competing values. These propositions warrant empirical testing by future research.

Collectively, the five papers in this special issue advance our understanding of the connection between the IS organization and value creation. The first two papers explore the value creation role of important firm-level factors such as strategic commitment and IT governance. The next two papers study value creation in IT service delivery and in application maintenance. The last paper investigates how IT creates value in the public sector, which complements the traditional dialog on business value of IT. We hope this special issue engages IS researchers and practitioners in an important dialog pertaining to IT-business value creation in a hyper-connected, highly volatile, complex world and extends the dialog beyond the private sector to the public sector. While many important questions pertaining to IT business value remained unanswered, we are concerned about a recent decrease in publications on this topic (Schryen, 2013). Although this special issue alone will not address all the unanswered questions, we hope it re-stimulates IS researchers' interest in this important topic and leads to high-quality and high-impact future research.

\section{References}

Aral, S. and Weill, P. (2007). IT Assets, Organizational Capabilities, and Firm Performance: How resource allocations and organizational differences explain performance variation, Organization Science 18(5): 763-780.

Carr, N.G. (2003). IT Doesn't Matter, Harvard Business Review 81(5): 41-49.

DeJarnett, L., Laskey, R. and Trainor, H.E. (2004). From the CIO Point of View: The' IT doesn't matter' debate, Communications of the Association for Information Systems 13(1): 26.

Gregory, R.W., Beck, R. and Keil, M. (2013). Control Balancing in Information Systems Development Offshoring Projects, MIS Quarterly 37(4): 1211-1232.

Grover, V. and Kohli, R. (2012). Cocreating IT Value: New capabilities and metrics for multifirm environments, MIS Quarterly 36(1): 225-232.

Han, K., Chang, Y.B. and Hahn, J. (2011). Information Technology Spillover and Productivity: The role of information technology intensity and competition, Journal of Management Information Systems 28(1): 115-146.

Kim, G., Shin, B., Kim, K.K. and Lee, H.G. (2011). IT Capabilities, ProcessOriented Dynamic Capabilities, and Firm Financial Performance, Journal of the Association for Information Systems 12(7): Article 1.

Lee, G. and Kwak, Y. H. (2012). An Open Government Maturity Model for Increasing Social Media-Based Public Engagement, Government Information Quarterly 29(4): 492-503. 
Oz, E. (2005). Information Technology Productivity: In search of a definite observation, Information \& Management 42(6): 789-798.

Petter, S., DeLone, W. and McLean, E.R. (2012). The Past, Present, and Future of ${ }^{*}$ IS Success', Journal of the Association for Information Systems 13(5): Article 2.

Schryen, G. (2013). Revisiting IS Business Value Research: What we already know, what we still need to know, and how we can get there, European Journal of Information Systems 22(2): 139-169.

Xia, W. and Lee, G. (2005). Complexity of Information Systems Development Projects: Conceptualization and measurement development, Journal of Management Information Systems 22(1): 45-83.

Yoo, Y., Henfridsson, O. and Lyytinen, K. (2010). Research Commentary - The New Organizing Logic of Digital Innovation: An agenda for information systems research, Information Systems Research 21(4): 724-735.

\section{About the Authors}

Gwanhoo Lee received the Ph.D. degree from the University of Minnesota. He is an Associate Professor in the Kogod School of Business at the American University. His current research interests include complexity and agility in information systems development, global teams, complex adaptive systems, social media, digital government, and information privacy. He has published his research in journals including MIS Quarterly, Journal of Management Information Systems, IEEE Transactions on Software Engineering, Communications of the ACM, and European Journal of Information Systems.

William H. DeLone received the Ph.D. degree from the University of California Los Angeles. He is a Professor in the Kogod School of Business at the American University. His current research interests include the assessment of information systems' effectiveness and value, e-government and public value, and the management of global software development. His research has been published in journals including Information Systems Research, MIS Quarterly, the Journal of
Management Information Systems, and the Journal of the Association of Information Systems.

Margaret Tan received the BComm degree from The University of Newcastle, the MBA degree from The University of Adelaide and the Ph.D. degree from The University of Queensland, Australia. She is currently the senior scientist at the Social and Cognitive Computing Department, Institute of High Performance Computing at the Agency for Science, Technology and Research in Singapore. Her current research interests include the strategic deployment and management of information technologies and infrastructure, the building of electronic governance and online trust in social media, information security, protection and privacy, e-government and the digital societies. She has published her research in the Information and Management, Decision Support Systems, Journal of Management Information Systems, International Journal of Electronic Commerce, Journal of the Association of Information Systems, Communications of the Association for Information Systems, Information Technology and People, Behavior \& Information Technology, Information Management \& Computer Security, Information, Communication \& Society, International Journal of Knowledge Management, and International Journal of Electronic Business.

Martha Corrales received the Ph.D. degree in a joint program with UT Austin and Tecnologico de Monterrey. She is currently a Professor at EGADE Business School, Tecnologico de Monterrey. Her current research interests include open innovation and business models; global virtual teams and virtual work models; and the assessment of innovation and entrepreneurial success for regional development. She has published her research in journals including Decision Sciences, Journal of Global Information Management, and the International Journal of Work Innovation. 